\section{Nasolacrimal duct intubation in the treatment of congenital nasolacrimal duct obstruction in older children}

S Okumuş ${ }^{1}$, V Öner², C Durucu ${ }^{3}$, E Coşkun ${ }^{1}$,

Ü Aksoy ${ }^{1}$, E Durucu ${ }^{4}$, L Şahin ${ }^{5}$ and I Erbağ $\mathrm{Cl}^{1}$

\begin{abstract}
Purpose The purpose of this study was to investigate the outcomes of nasolacrimal duct intubation in the primary treatment of congenital nasolacrimal duct obstruction (CNLDO) in children aged 7 years and older. Methods Thirty children aged $\geq 7$ years who underwent primary unilateral nasolacrimal duct intubation because of CNLDO were enrolled in this study. CNLDO diagnosis was based on signs and symptoms including typical epiphora, increased tear meniscus, recurrent or persistent mucopurulent discharge, and an abnormal dye disappearance test (DDT). Surgical success was defined as complete resolution of previous signs and symptoms and DDT grade $\mathbf{0} \mathbf{- 1}$.

Results The mean age was $10.7 \pm 2.5$ years (ranging from 7 to 15 years). Of the $\mathbf{3 0}$ patients, 18 were male and 12 were female. The mean follow-up period was $8.8 \pm 3.4$ months (ranging from 6 to 16 months). The mean silicone tube removal time was $4.6 \pm 1.1$ months (ranging from 3 to 6 months). The complete resolution of signs and symptoms with DDT grade $\mathbf{0}-\mathbf{1}$ was observed in 22 of 30 cases $(73.3 \%)$ during the follow-up period. The mean age of the patients with unsuccessful outcomes was $12.7 \pm 1.4$ years, whereas that of the patients with successful outcomes was $10.0 \pm 2.4$ years, and the difference was statistically significant $(P=0.006)$. No serious intra- and/or postoperative complication was observed. Conclusions The current study demonstrates that nasolacrimal duct silicone intubation with intranasal endoscopic visualization has favorable outcomes as a primary treatment of persistent CNLDO in children aged 7 years and older. It can be used to reduce the need
\end{abstract}

for dacryocystorhinostomy which is a more invasive procedure.

Eye (2016) 30, 85-88; doi:10.1038/eye.2015.189; published online 9 October 2015

\section{Introduction}

Congenital nasolacrimal duct obstruction (CNLDO), an extremely common cause of epiphora in the pediatric population, is caused by a failure of nasolacrimal duct canalization. ${ }^{1}$

The obstruction is usually at the level of the Hasner valve, at the distal end of the duct. ${ }^{1}$ Fortunately, spontaneous resolution occurs in most of the cases by the age of 1 year. ${ }^{2}$ Probing has been found to have high success rates in the treatment of cases whose obstruction does not resolve spontaneously. ${ }^{3,4}$ However, it has been shown that the success rate of probing diminishes with increasing age. ${ }^{5}$

Nasolacrimal duct silicone intubation is generally reserved for patients with persistent obstruction after failed probing or as a primary method in older children. ${ }^{6}$ The procedure has been used to reduce the need for dacryocystorhinostomy (DCR). It has been displayed that nasolacrimal duct intubation is a successful procedure in children aged up to 7 years. ${ }^{7-11}$ On the other hand, the studies including children older than 7 years are very rare, and those studies had study population with wide age ranges also including younger children. ${ }^{12,13}$ To the best of our knowledge, there is no study evaluating the success rates of nasolacrimal duct intubation for the treatment of CNLDO in only children older than 7 years of age. Therefore, in the current study, we aimed to investigate the outcomes of primary
${ }^{1}$ Department of Ophthalmology, Gaziantep University Medical School, Gaziantep, Turkey

${ }^{2}$ Department of Ophthalmology, Recep Tayyip Erdoğan University Medical School, Rize, Turkey

${ }^{3}$ Department of Otorhinolaryngology, Gaziantep University Medical School, Gaziantep, Turkey

${ }^{4}$ Department of Ophthalmology, Gaziantep Ersin Aslan State Hospital, Gaziantep, Turkey

${ }^{5}$ Department of Anesthesiology, Gaziantep University Medical School, Gaziantep, Turkey

Correspondence:

$\checkmark$ Öner, Department of Ophthalmology, Recep Tayyip Erdoğan University Medical School, Rize 53100, Turkey Tel: +90 4642130491 ; Fax: +90 4642170364 E-mail: veysioner@ gmail.com

Received: 10 May 2015 Accepted in revised form: 8 August 2015 Published online: 9 October 2015 
nasolacrimal duct intubation in the treatment of CNLDO in children older than 7 years.

\section{Methods}

Children aged $\geq 7$ years with previously untreated epiphora since birth who underwent primary nasolacrimal duct intubation for management of CNLDO were enrolled in this prospective study. The diagnosis of CNLDO was based on signs and symptoms including typical epiphora, increased tear meniscus, recurrent or persistent mucopurulent discharge, and an abnormal dye disappearance test. ${ }^{14}$ Of the 36 subjects, 3 with punctal occlusion and 3 with bicanalicular obstruction were excluded from the study. Patients with Down syndrome, a history of previous probing or any other nasolacrimal duct surgery, and a midline facial anomaly were excluded from the study. Thirty patients met the inclusion criteria. All subjects and parents were informed about the surgical procedure and the informed consents were obtained. The study was conducted in accordance with the Tenets of the Declaration of Helsinki, and it was approved by the Local Ethics Committee.

All nasolacrimal intubations were performed under general anaesthesia with direct intranasal endoscopic visualization (using a $30^{\circ} / 2.7 \mathrm{~mm}$ nasal endoscope) by the same surgeon (SO). Before the intubation procedure, a cotton wool applicator soaked in $2 \%$ lidocaine with adrenaline $0.0125 \mathrm{mg} / \mathrm{ml}$ was placed in the nasal cavity for $10 \mathrm{~min}$. After dilating the upper and lower puncta and then probing with a Bowman probe, the metal probes which were fixed to the silicone tubing were passed into the nasolacrimal duct and nasal cavity via the upper and lower canaliculus. The distal ends of the probes were caught by a small pediatric nasal forceps, and tied together (Figure 1). Topical corticosteroids and antibiotics were given to the patients for 10 days, postoperatively. All tubes were removed under general anaesthesia. Intra- and/or post-operative complications were recorded.

After the first follow-up visit of week 1, patients were examined for signs and symptoms and dye disappearance test monthly. Surgical success was defined as complete resolution of previous signs and symptoms and dye disappearance test grade $0-1$. A failure of intubation procedure, absence of improvement, or the worsening of the signs and symptoms after a successful intubation procedure was classified as surgical failure. Patients with unsuccessful outcomes were recommended to undergo DCR.

\section{Statistical analysis}

SPSS version 16.0 was used for statistical analysis. The distributions of variables were evaluated with
Kolmogorov-Smirnov test. Student $t$-test and Chi-Square test were used to compare the continuous and categorical variables of the patients with successful and unsuccessful results. A $P$-value of $<0.05$ was accepted as statistically significant.

\section{Results}

The mean age was $10.7 \pm 2.5$ years (ranging from 7 to 15 years). Of the 30 patients, 18 were male and 12 were female. All patients had initiation of symptoms of CNLDO within the first month after birth. A bicanalicular silicone tube was successfully placed in all patients except for two cases for which probing could not be achieved. Inferior turbinate infracture was required in six $(20 \%)$ of the cases. The mean follow-up period was $8.8 \pm 3.4$ months (ranging from 6 to 16 months). The mean silicone tube removal time was $4.6 \pm 1.1$ months (ranging from 3 to 6 months).

Three patients had symptomatic lacrimal fistula located inferonasal to the medial canthus, preoperatively, which closed spontaneously after the intubation procedure. Although the silicone tubing was welltolerated in the most of the cases, three patients (10\%) experienced epiphora and minimal mucopurulent secretion with the tubes in place which resolved after the removal of the tubes. The complete resolution of signs and symptoms with dye disappearance test grade $0-1$ was observed in 22 of 30 cases $(73.3 \%)$ during the follow-up period. In six cases (20\%), improvement of the signs and symptoms could not be achieved after the procedure, and in two cases (6.7\%), the intubation procedure could not be performed because of the severe obstruction in the nasolacrimal duct.

The mean age of the patients with unsuccessful outcomes was $12.7 \pm 1.4$ years, whereas that of the patients with successful outcomes was $10.0 \pm 2.4$ years and the difference was statistically significant $(P=0.006)$. Gender and time at mean silicone tube removal (both $P>0.05)$ were not statistically different. No serious intraand/or post-operative complications including excessive bleeding, punctal damage, 'cheese wiring', dacryocystitis, or pyogenic granuloma formation were observed.

\section{Discussion}

The present study showed that silicone intubation of nasolacrimal duct with nasal endoscopic visualization had favorable results as a primary treatment of persistent CNLDO in children older than 7 years of age.

CNLDO is a common lacrimal system disorder in children. Conservative therapy has been found to be sufficient in most cases during the first 12 months, and probing has been proposed as the most effective 

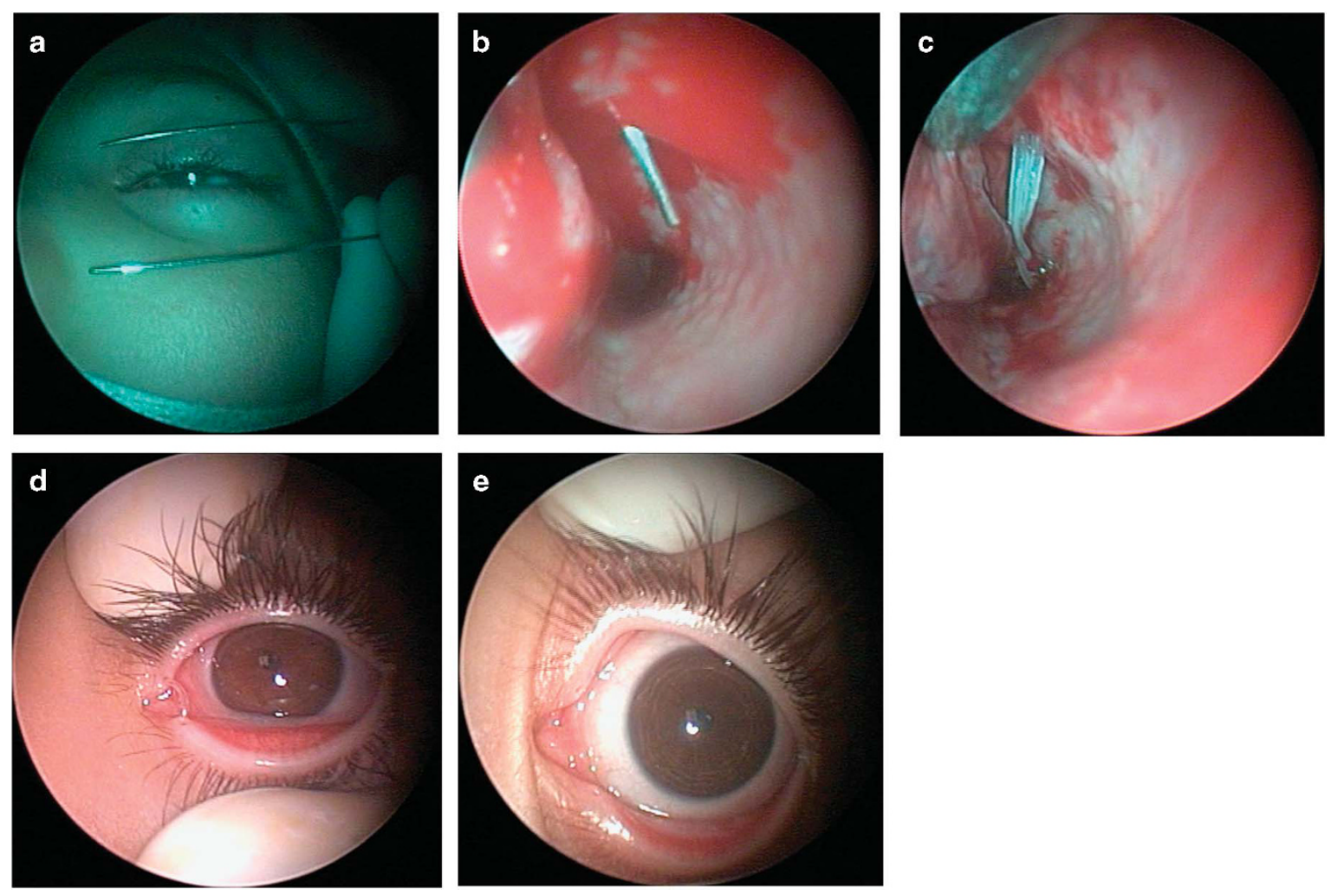

Figure 1 Pictures of nasolacrimal duct silicon intubation procedure showing metal probes fixed to the silicone tubing before the surgery (a), the entering of metal probes to the inferior meatus under endoscopic visualization (b), both arms of silicon tubes retrieved from the inferior meatus (c), bicanalicular silicone tubes at the medial canthus after the procedure (d), and the appearance of the eye after the removal of the silicon tubes (e).

procedure in cases aged between 12 and 18 months.,15 Although silicone intubation is generally used after failure of conservative therapy and probing, it has been suggested as the primary procedure in children older than $1.5-2$ years, owing to the decreasing success of probing with age. ${ }^{16}$ Silicone tubing avoids annular obstruction and contraction inside the nasolacrimal canal during wound healing, by acting as a temporary stent.

Previous studies have shown high success rates of silicone intubation in the treatment of CNLDO in children aged up to 7 years. ${ }^{7-11}$ Orhan $e t a l^{9}$ used silicone intubation with the help of nasal endoscopic viewing in children with an age range of 18-48 months in the treatment of CNLDO. They found a 100\% success rate for a follow-up period ranging from 4 to 24 months. Repka et $a l^{8}$ reported a $90 \%$ success rate in children aged 6 to 45 months with no prior nasolacrimal surgical procedure. Andalib et $a l^{10}$ achieved an $86.2 \%$ success rate for monocanalicular and an $89 \%$ success rate for bicanalicular silicone intubation in children younger than 7 years of age. In our study, the success rate was slightly lower $(73.3 \%)$ than in the previous studies, probably owing to the fact that success of nasolacrimal duct intubation reduces with increasing age. ${ }^{17,18}$ In addition, in accordance with the previous studies, ${ }^{17,18}$ we showed that the mean age of the patients with unsuccessful results was significantly higher than that of the patients with successful results. This may be caused by increased fibrosis at the site of obstruction in older children.

Few studies have investigated the results of nasolacrimal duct silicone intubation in children with wider age ranges. ${ }^{12,13}$ Aggarwal et al ${ }^{12}$ achieved complete resolution of symptoms in $80 \%$ of patients, in a population including children with ages varied from 11 months to 9 years. They stated that this approach might avoid a DCR in over $80 \%$ of children with epiphora. Kraft et al ${ }^{13}$ analyzed the outcomes of silicone intubations in children aged 6 months to 16 years and found an overall success rate of $80.3 \%$. However, in the aforementioned studies, no specific analysis for the patients older than 7 years were undertaken. To the best of our knowledge, we are the first in the literature to report the results of silicone intubation in children aged 7 years or older.

External and endonasal DCR have also been used in the treatment of the older children with persistent CNLDO. ${ }^{19,20}$ However, silicone intubation is a less invasive procedure compared with external or endonasal 
DCR. According to our results, in older children with persistent CNLDO, silicone intubation procedure may reduce the need for DCR, which has greater morbidity.

We used direct intranasal endoscopic visualization intraoperatively for the retrieval of the silicone tubes. Retrieval of metal probes through the inferior meatus can be difficult and complicated by the traumatic mucosal injuries around the inferior turbinate. Direct endoscopic viewing reduces the risk of nasal mucosal trauma. In addition, it avoids the development of iatrogenic false passages and diminishes the requirement for inferior turbinate infracture. In our study, silicone intubation did not require inferior turbinate infracture in most of the patients $(80 \%)$ owing to intranasal endoscopic visualization.

Limitations of the present study were the relative small sample size and short follow-up period. Studies with larger sample sizes, longer follow-up periods and, in addition, a similar study with monocanalicular intubation (as this would avoid the use of a second anaesthetic) would make useful contributions to the literature in the treatment of older children with persistent CNLDO.

In conclusion, the current study demonstrates that nasolacrimal duct silicone intubation with intranasal endoscopic visualization has favorable outcomes as a primary treatment of persistent CNLDO in children aged 7 years and older. It can be used to reduce the need for DCR, which is a more invasive procedure.

\section{Summary}

\section{What was known before}

- It is known that nasolacrimal duct intubation is a successful procedure in the treatment of congenital nasolacrimal duct obstruction (CNLDO) in children aged up to 7 years.

\section{What this study adds}

- The current study demonstrates that nasolacrimal duct silicon intubation with intranasal endoscopic visualization has favorable outcomes as a primary treatment of persistent CNLDO in children older than 7 years of age.

\section{Conflict of interest}

The authors declare no conflict of interest.

\section{References}

1 Schnall BM. Pediatric nasolacrimal duct obstruction. Curr Opin Ophthalmol 2013; 24: 421-424.

2 Petersen RA, Robb RM. The natural course of congenital obstruction of the nasolacrimal duct. J Pediatr Ophthalmol Strabismus 1978; 15: 246-250.
3 Stager D, Baker JD, Frey T, Weakley DR Jr, Birch EE. Office probing of congenital nasolacrimal duct obstruction. Ophthalmic Surg 1992; 23: 482-484.

4 Katowitz JA, Welsh MG. Timing of initial probing and irrigation in congenital nasolacrimal duct obstruction. Ophthalmology 1987; 94: 698-705.

5 Robb RM. Success rates of nasolacrimal duct probing at time intervals after 1 year of age. Ophthalmology 1998; 105: 1307-1309; discussion 1309-1310.

6 Al-Faky YH, Al-Sobaie N, Mousa A, Al-Odan H, Al-Huthail R, Osman E et al. Evaluation of treatment modalities and prognostic factors in children with congenital nasolacrimal duct obstruction. J AAPOS 2012; 16: 53-57.

7 Migliori ME, Putterman AM. Silicone intubation for the treatment of congenital lacrimal duct obstruction. Ophthalmology 1988; 95: 792-795.

8 Pediatric Eye Disease Investigator Group, Repka MX, Melia BM, Beck RW, Atkinson CS, Chandler DL, Holmes JM et al. Primary treatment of nasolacrimal duct obstruction with nasolacrimal duct intubation in children younger than 4 years of age. J AAPOS 2008; 12: 445-450.

9 Orhan M, Onerci M. Intranasal endoscopic silicone intubation for congenital obstruction of the nasolacrimal duct in children. Int J Pediatr Otorhinolaryngol 1997; 41: 273-278.

10 Andalib D, Gharabaghi D, Nabai R, Abbaszadeh M. Monocanalicular versus bicanalicular silicone intubation for congenital nasolacrimal duct obstruction. J AAPOS 2010; 14: 421-424.

11 Yazici B, Akarsu C, Salkaya M. Silicone intubation with the Ritleng method in children with congenital nasolacrimal duct obstruction. J AAPOS 2006; 10: 328-332.

12 Aggarwal RK, Misson GP, Donaldson I, Willshaw HE. The role of nasolacrimal intubation in the management of childhood epiphora. Eye (Lond) 1993; 7: 760-762.

13 Kraft SP, Crawford JS. Silikon tube intubation in disorders of the lacrimal system in children. Am J Ophthalmol 1982; 94: 290-299.

14 MacEwen CJ, Young JD. The fluorescein disappearance test (FDT): an evaluation of its use in infants. J Pediatr Ophthalmol Strabismus 1991; 28: 302-305.

15 Nelson LB, Calhoun JH, Menduke H. Medical management of congenital nasolacrimal duct obstruction. Pediatrics 1985; 76: 172-175.

16 Paul TO, Shepherd R. Congenital nasolacrimal duct obstruction: natural history and the timing of optimal intervention. J Pediatr Ophthalmol Strabismus 1994; 31: 362-367.

17 Lueder GT. Balloon catheter dilation for treatment of persistent nasolacrimal duct obstruction. Am J Ophthalmol 2002; 133: 337-340.

18 Welsh MG, Katowitz JA. Timing of silastic tubing removal after intubation for congenital nasolacrimal duct obstruction. Ophthal Plast Reconstr Surg 1989; 5: 43-47.

19 de Souza CE, Nisar J, de Souza RA. Pediatric endoscopic dacryocystorhinostomy. Otolaryngol Head Neck Surg 2012; 147: 335-337.

20 Ali MJ, Gupta H, Naik MN, Honavar SG. Endoscopic guided single self-linking silicone stent in pediatric external dacryocystorhinostomy. Minim Invasive Ther Allied Technol 2013; 22: 266-270. 